\title{
Non-Mass Forming Isolated Omental Panniculitis: A Case Report
}

\section{Keishi Hakoda', Masanori Yoshimitsu ${ }^{1 *}$, Ichiro Omori ${ }^{1}$, Masashi Miguchi ${ }^{1}$, Toshihiko Kohashi ${ }^{1}$, Hideki Ohdan², Naoki Hirabayashi ${ }^{1}$}

\author{
${ }^{1}$ Department of Surgery, Hiroshima City Asa Citizens Hospital, Hiroshima, Japan \\ ${ }^{2}$ Department of Gastroenterological and Transplant Surgery, Applied Life Sciences, Institute of Biomedical \& Health Sciences, \\ Hiroshima University, Hiroshima, Japan \\ Email: *m4432@asa-hosp.city.hiroshima.jp
}

How to cite this paper: Hakoda, K., Yoshimitsu, M., Omori, I., Miguchi, M., Kohashi, T., Ohdan, H. and Hirabayashi, N. (2017) Non-Mass Forming Isolated Omental Panniculitis: A Case Report. Case Reports in Clinical Medicine, 6, 211-216. https://doi.org/10.4236/crcm.2017.67021

Received: June 18, 2017

Accepted: July 25, 2017

Published: July 28, 2017

Copyright (c) 2017 by authors and Scientific Research Publishing Inc. This work is licensed under the Creative Commons Attribution International License (CC BY 4.0).

http://creativecommons.org/licenses/by/4.0/

\begin{abstract}
A 61-year-old man presenting with abdominal pain and fever refractory to antibiotics underwent diagnostic laparoscopy and non-mass-forming isolated omental panniculitis was identified. He presented with left-upper-quadrant abdominal pain. Laboratory data and the CT findings suggested intraabdominal bacterial disease in the splenic flexure, which we treated with antibiotics and fasting. He clinically improved once, but later relapsed with abdominal pain migration to the left-lower-quadrant. CT re-examination revealed no inflammation in the splenic flexure, but attenuation of adipose tissue in the greater omentum. We partially extracted the greater omentum during diagnostic laparoscopy and diagnosed omental panniculitis and administered steroids. He improved and was discharged three days after starting oral prednisone and is recurrence-free with a close follow-up. The characteristic CT feature of omentum panniculitis is a high-density fatty mass, but we noted only an attenuation of adipose tissue in the greater omentum. Diagnositic laparoscopy is useful for diagnosing this condition.
\end{abstract}

\section{Keywords}

Omental Panniculitis, Computed Tomography, Laparoscopy

\section{Introduction}

Isolated omental panniculitis is a rare form of intraabdominal panniculitis, mainly involving the mesenteric adipose tissue of the small intestine or colon [1] [2]. The characteristic computed tomography (CT) features of intraabdominal panniculitis described in previous reports have ranged from increased attenuation to a solid soft tissue mass. In contrast, the only CT finding described for 
isolated omental panniculitis is a high-density fatty mass. Diagnoses of isolated omental panniculitis are traditionally made via exploratory laparotomy or CTguided biopsy [3] [4] [5] [6].

We herein report a case of isolated omental panniculitis that showed only attenuation of the adipose tissue of the greater omentum. Exploratory laparoscopy proved to be useful in diagnosing this condition.

\section{Case Report}

A 61-year-old man presented with a 1-week history of intermittent left upper quadrant abdominal pain and a fever $\left(38.3^{\circ} \mathrm{C}\right)$. His medical history and family history were unremarkable. Laboratory tests revealed an elevated white blood cell count $\left(19200 / \mathrm{mm}^{3}\right.$; reference, $\left.4000-9000 / \mu \mathrm{L}\right)$ and increased levels of Creactive protein (CRP, $24.8 \mathrm{mg} / \mathrm{dL}$; reference, $0.3-0.0 \mathrm{mg} / \mathrm{dL}$ ) and procalcitonin (PCT, $1.05 \mathrm{ng} / \mathrm{ml}$; reference, $0.49-0.00 \mathrm{ng} / \mathrm{mL}$ ). CT revealed attenuation of the adipose tissue in the splenic flexure and wall-thickening of the nearby transverse colon. A large amount of ascites from the surface of the liver to the pelvis was noted in the left thoracic cavity, along with plural effusion suggesting involvement in the inflammation. There was no free air (Figure 1). We started treatment with antibiotics (PIPC/TAZ $4.5 \mathrm{~g}$, every $8 \mathrm{~h}$ ), fasting and fluid therapy under a diagnosis of bacterial intraabdominal inflammation. The clinical data improved once, but six days after admission, the patient's condition became exacerbated, and the abdominal pain migrated to the left lower quadrant.

CT re-examination revealed no attenuation of adipose tissue in the splenic flexure and also decreased ascites and pleural effusion; however, attenuation of the adipose tissue of the greater omentum was noted, suggesting inflammation of the greater omentum. This prompted us to consider a diagnosis of omental panniculitis (Figure 2).

Diagnostic laparoscopy was performed to exclude any other abdominal inflammatory disease definitively, and we conducted a surgical biopsy of the greater omentum. The omentum was diffusely thick and hard and had adhered to the abdominal wall. We divided the adhesions and extracted the grater omentum via the camera port incision and partially resected it.

An examination of the pathology specimens revealed acute inflammation with
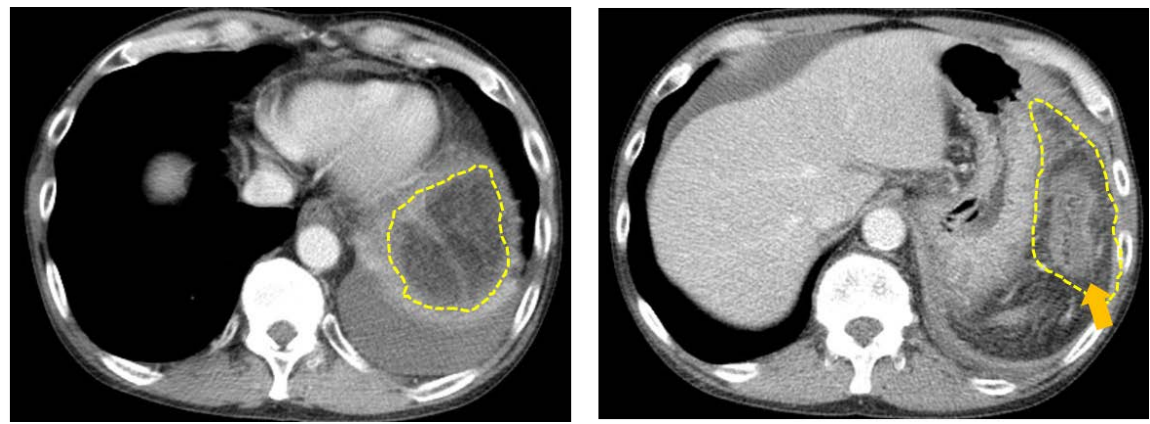

Figure 1. Enhanced CT revealed attenuation of the adipose tissue in the splenic flexure (dotted line area) and wall thickening of the nearby transverse colon (orange arrow). 
infiltration of numerous inflammatory cells, immature fibroblasts, fatty necrosis and fibrosis, findings consistent with omental panniculitis without malignancy (Figure 3).

The patient was started on prednisone $20 \mathrm{mg}$ (intravenous) daily. His symptoms gradually ameliorated, and he was able to eat without nausea. He was discharged 3 days after starting oral prednisone $(20 \mathrm{mg})$ and has been closely followed-up without recurrence.

\section{Discussion}

Isolated omental panniculitis is a rare form of intraabdominal panniculitis, mainly involving the mesenteric adipose tissue of the small intestine or colon [1] [2].

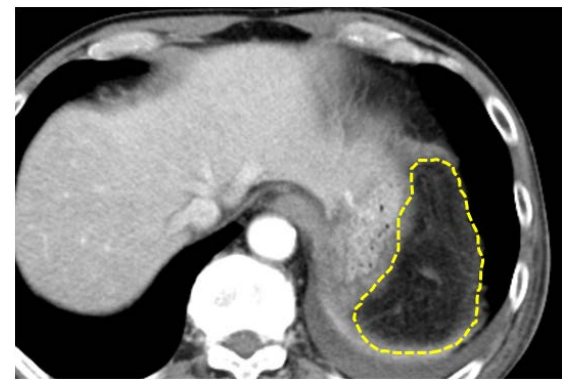

(a)

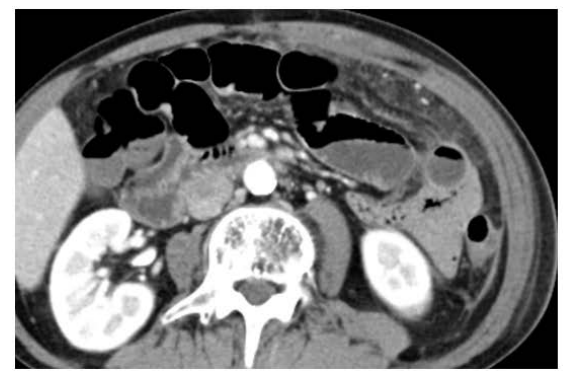

(c)

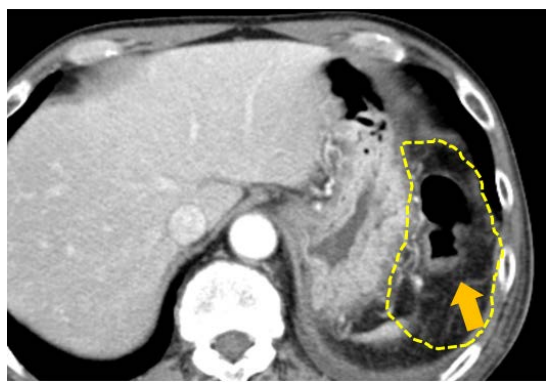

(b)

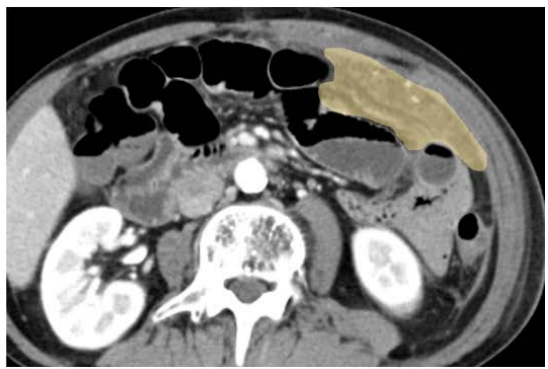

Figure 2. At the sixth hospital day, enhanced CT re-examination revealed no attenuation of the adipose tissue in the splenic flexure (dotted line area) and decreased ascites and pleural effusion (orange arrow) (a, b); however, attenuation of the adipose tissue of the greater omentum was noted (c: encircled region).
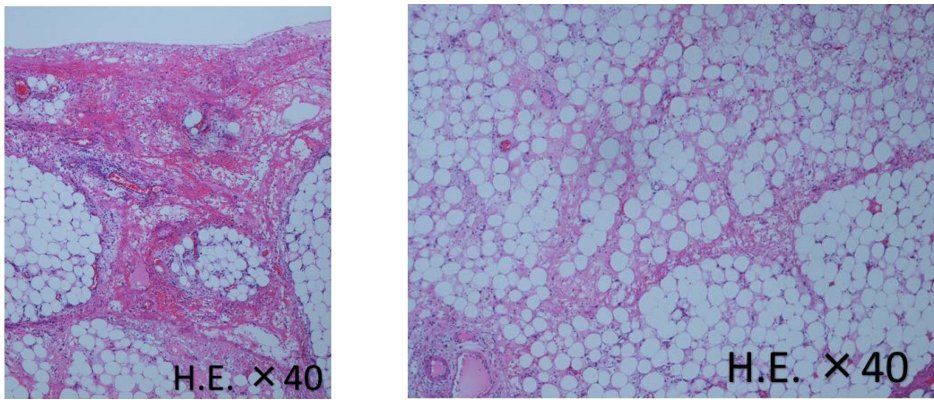

Figure 3. On hematoxylin-eosin staining, acute inflammation was observed with infiltration of numerous inflammatory cells, immature fibroblasts, fatty necrosis and fibrosis of the fat tissue. 
This study highlighted two major clinical issues. First, isolated omental panniculitis can present as only attenuation of the adipose tissue without a highdensity fatty mass. Second, diagnostic laparoscopy is useful for the diagnosis of this condition.

Isolated omental panniculitis can present as only the attenuation of adipose tissue. The characteristic computed tomography (CT) features of intraabdominal panniculitis described in previous reports have ranged from increased attenuation to a solid soft tissue mass. In contrast, the only CT finding described for isolated omental panniculitis (classical finding) has been a high-density fatty mass [3] [4] [5] [7].

The natural course of omental panniculitis is considered to be the same as that of mesenteric panniculitis that first, starting with lipodystrophy, in which a layer of foamy macrophages replaces the fat, followed by the infiltration of plasma cells and a few polymorphonuclear leukocytes, foreign-body giant cells and foamy macrophages, before finally resulting in a retractile stage distinguished by collagen deposition and the diffuse presence of necrosis and fibrosis that contributes to tissue retraction. Collagen deposition leads to scarring and retraction of the omental adipose tissue, which in turn leads to the formation of abdominal masses and obstructive symptoms [7]. The previously reported CT findings for omental panniculitis of a high-density fatty mass are suggestive of the retractile stage of the disease. Earlier stages of the disease have not been detected and are therefore not treated as omental panniculitis. The present case is therefore unusual, as we were able to pathologically diagnose the patient and his treat omental panniculitis despite the absence of a fatty mass.

Laparoscopy proved useful for the diagnosis of this condition in the present patient. In previous studies of isolated omental panniculitis, the CT findings revealed a high-density fatty mass, and diagnoses were made by diagnostic laparotomy or CT-guided biopsy for extraction [3] [4] [5] [6]. As the present patient had no fatty mass on CT nor any other findings that might lead to a definitive diagnosis, a surgical biopsy was needed, which we performed via low-invasive diagnostic laparoscopy (single port).

The pathogenic mechanism of mesenteric panniculitis has been implied to be a non-specific response to a wide variety of stimuli, such as previous abdominal trauma or surgery, autoimmune reactions, infection and vascular insufficiency [8]. However, previous cases of omental panniculitis have seemed idiopathic or been caused by autoimmune reactions to medication [3] [4] [5] [6] [9]. In the present case, the patient seemed to demonstrated abdominal bacterial infectious disease which thereafter developed into omental panniculitis, considering the patient's clinical course of initial improvement in symptoms and laboratory data with antibiotics followed by exacerbation and abdominal pain migration.

Present patient had severe abdominal symptoms, and his laboratory data worsened to the point that immediate treatment was considered necessary. If omental panniculitis progresses, intestine stenosis may occur, necessitating intestinal resection [3] [6], so the treatment of symptomatic patients with steroids 
or anti-inflammatory medication should be considered [10].

\section{Conclusion}

In conclusion, isolated omental panniculitis can present as only the attenuation of adipose tissue of the greater omentum without any findings of a high-density fatty mass, and exploratory laparoscopy can be useful for the diagnosis of this condition. We must be aware that isolated omental panniculitis can manifest with CT findings other than those expected. Some cases of isolated omental panniculitis may remain unrecognized, and thus there may be hidden cases of isolated omental panniculitis treated with only antibiotics or fasting under a misdiagnosis as another intraabdominal inflammation disease. Dignostic laparoscopy can definitively exclude other abdominal inflammatory diseases, and a surgical biopsy of the greater omentum is less invasive than laparotomy. When encountering patients with abdominal pain refractory to antibiotics, omental panniculitis should be considered as a differential diagnosis, and diagnostic laparoscopy may need to be performed.

\section{Conflict to Interest}

The authors declare no conflicts of interest in association with this report.

\section{Funding}

There is no funding for this case report.

\section{Ethical Approval}

The design of this report has been approved by our institute ethical committee

\section{Consent}

Written informed consent was obtained from the patient for the publication of this case report and any accompanying images. A copy of the written consent form is available for review by the Editor-in-Chief of this journal.

\section{References}

[1] Parra-Davila, E., McKenney, M.G., Sleeman, D., Hartmann, R., Rao, R.K., McKenney, K., and Compton, R.P. (1998) Mesenteric Panniculitis: Case Report and Literature Review. The American Surgeon, 64, 768-771.

[2] Sabaté, J.M., Torrubia, S., Maideu, J., Franquet, T., Monill, J.M. and Pérez, C. (1999) Sclerosing Mesenteritis: Imaging Findings in 17 Patients. American Journal of Roentgenology, 172, 625-629. https://doi.org/10.2214/ajr.172.3.10063848

[3] Hirono, S., Sakaguchi, S., Iwakura, S., Masaki, K., Tsuhada, K. and Yamaue, H. (2005) Idiopathic Isolated Omental Panniculitis. Journal of Clinical Gastroenterology, 39, 79-80.

[4] Lheureux, P., Matos, C., Charlier, P.H., Van Romphey, A., Rickaert, F., Van Gansbeke, D. and Askenasi, R. (1987) Omental Panniculitis: An Unusual Cause of Acute Appendiceal Syndrome. Annals of Emergency Medicine, 16, 224-226. https://doi.org/10.1016/S0196-0644(87)80022-7 
[5] Jeon, E.J. and Cho, S.M. (2009) Idiopathic Isolated Omental Panniculitis Confirmed by Percutaneous CT-Guided Biopsy. Gut and Liver, 3, 321-324.

https://doi.org/10.5009/gnl.2009.3.4.321

[6] Masulovic, D., Jovanovic, M., Ivanovic, A., Stojakov, D., Micev, M., Stevic, R., Filipovic, A. and Galun, D. (2016) Sclerosing Mesenteritis Presenting as a Pseudotumor of the Greater Omentum. Medical Principles and Practice, 25, 93-95. https://doi.org/10.1159/000441454

[7] Wat, S.Y., Harish, S., Winterbottom, A., Choudhary, A.K. and Freeman, A.H. (2006) The CT Appearances of Sclerosing Mesenteritis and Associated Diseases. Clinical Radiology, 61, 652-658. https://doi.org/10.1016/j.crad.2006.02.012

[8] Emory, T.S., Monihan, J.M., Carr, N.J. and Sobin, L.H. (1997) Sclerosing Mesenteritis, Mesenteric Panniculitis and Mesenteric Lipodystrophy: A Single Entity? The American Journal of Surgical Pathology, 21, 392-398.

https://doi.org/10.1097/00000478-199704000-00004

[9] Rozin, A., Bishara, B., Ben-Izhak, O., Fischer, D., Carter, A. and Edoute, Y. (2000) Fibrosing Omental Panniculitis and Polyserositis Associated with Long-Term Treatment by Paroxetine. Israel Medical Association Journal, 2, 714-716.

[10] Akram, S., Pardi, D.S., Schaffner, J.A. and Smyrk, T.C. (2007) Sclerosing Mesenteritis: Clinical Features, Treatment, and Outcome in Ninety-Two Patients. Clinical Gastroenterology and Hepatology. The Official Clinical Practice Journal of the American Gastroenterological Association, 5, 589-596; quiz 523-584.

Scientific Research Publishing

\section{Submit or recommend next manuscript to SCIRP and we will provide best} service for you:

Accepting pre-submission inquiries through Email, Facebook, LinkedIn, Twitter, etc. A wide selection of journals (inclusive of 9 subjects, more than 200 journals)

Providing 24-hour high-quality service

User-friendly online submission system

Fair and swift peer-review system

Efficient typesetting and proofreading procedure

Display of the result of downloads and visits, as well as the number of cited articles

Maximum dissemination of your research work

Submit your manuscript at: http://papersubmission.scirp.org/

Or contact crcm@scirp.org 